\title{
Is the Medical Community Adequately Prepared for the Future Challenges in Facial Allotransplantation?
}

\author{
Evangelos Sarantopoulos* \\ Department of Plastic and Aesthetic Surgery, Fabrikschon, Klosterberg 19, 4051 Basel, Switzerland/TUM Graduate School Munich, Germany
}

*Corresponding author: E. Sarantopoulos, MD MRM MSc, Department of Plastic and Aesthetic Surgery, Fabrikschon, Klosterberg 19, 4051 Basel, Switzerland. E-mail: esarantopoulos@yahoo.com

Received date: June 25, 2015, Accepted date: October 15, 2015, Published date: October 25, 2015

Copyright: @ 2015, Sarantopoulos E. This is an open-access article distributed under the terms of the Creative Commons Attribution License, which permits unrestricted use, distribution, and reproduction in any medium, provided the original author and source are credited.

\section{Introduction}

Transplantation continues to push the frontiers of medicine into domains that lead to troublesome ethical questions. In 1954 Dr Joseph Murray, a plastic and reconstructive surgeon at Brigham and Women's hospital in Boston, performed the first successful renal transplantation between identical twins. Since then, the field of transplantation has evolved to include the successful transplantation of heart, lungs, liver, pancreas, and small bowel [1]. Nowadays, different teams around the world consider performing a human facial transplantation. Facial allotransplantation truly allows for the axiomatic replacement of "like with like." It permits the reconstructive surgeon to replace exactly the tissues that are missing, without incurring the donor deficit that accompanies traditional techniques [2]. Indeed, there are critical specialized structures in the face (i.e. eyelids, lips, nose) whose exact functions cannot be replicated via current autologous surgical techniques [3].

\section{History of Facial Allotransplantation}

In 2005, a French team performed the first successful face transplant. Since then, 31 facial allotransplantations have been performed in France, China, the United States, Belgium, Spain, Poland and Turkey. Three recipients are now dead as a result of tissue rejection and infection [4]. Critics question whether the benefit is worth the risk. Plastic surgeons weigh Sir Harold Gillies' reconstructive principle of replacing like with like against the Hippocratic dictum primum non nocere, or "first do no harm." The risks of lifelong immunosuppression, including infection, malignancy, and end-organ toxicity, seem prima facie prohibitive in the context of a nonlifesaving intervention. But severe facial disfigurement to the degree that confers eligibility consideration is not a trivial thing. These are not merely "cosmetic defects," but conditions that render the patient unable to properly eat, breathe, or speak. Furthermore, the face is essential for communication and relating to others, which is the foundation for how we understand ourselves as human $[5,6]$. Restoring the face with composite tissue allotransplantation can provide results that are unattainable with current reconstructive techniques.

There is no doubt that facial transplantation allows plastic and reconstructive surgeons to follow one of their first principles: replace like with like. When successful, replacing like with like results in a superior aesthetic and functional outcome for the patient. Achieving this outcome is important for restoration of the severely disfigured individual, in as much as the face constitutes an essential part of what makes us human. Facial tissue allotransplantation has the potential to restore a functional face with significantly fewer operations than traditional reconstructive techniques and makes it possible to reconstruct parts of the face that cannot be restored by traditional means.

\section{Ethical Issues in Facial Allotransplantation}

Much of the discussion of the risks associated with facial transplantation is utilitarian. It includes, for example, the arguments that functional recovery may not be as good as hoped, or that the donation of facial tissue may cause significant distress within the donor's family, or that having a face that is not his or her own may be an insurmountable psychological hurdle for the patient. These are all outcome-based concerns, not normative proscriptions against performing a transplant. They define what is to be weighed on the "risks" side of the equation. Hence proper patient selection becomes a key point [7]. There is also a lot of discussion regarding the ethics of facial transplantation, because due to the technical progress in facial transplantation the frontiers of medical ethics are again being tested. Not long ago the pressing ethical issues in transplantation concerned the scarcity of donated organs and the deaths of potential recipients. With the relatively recent advent of human face transplantation, however, ethical reflection has shifted to the need to weigh the risks the patient assumes for the sake of receiving a donated organ that, unlike a heart or liver, is not necessary for his or her survival $[8,9]$. To date, 31 facial transplants have been performed worldwide, and the procedure is expected to be more common in the years ahead. In more recent ethical discussions, some new issues have become prominent, such as patient selection for face transplantation, the inability of severely disfigured patients to lead normal lives, and the high costs of face transplantation [10]. In a review of the medical literature, Kiwanuka and coauthors identified 110 articles discussing the ethics of face transplantation. Published from 2002 to 2012, nearly half of the papers appeared in the year before and after the first facial transplantperformed by a French team in 2005 . Since then, the number of ethical discussions on face transplantation has gradually decreased [11]. The papers showed a "time-related trend" in ethical positions. All of the articles published in 2002 concluded that face transplantation was not ethically justified. By 2008, all published papers acknowledged the ethical concerns, but concluded that they were outweighed by the benefits of successful facial transplant. The researchers identified a core group of 15 topics that recurred through the years. The most common issues were related to "identity change/psychological effects," the need for lifelong immunosuppressive drugs to prevent rejection of the transplanted face, and the risk versus benefits of face transplantation.

Although many topics have been addressed regarding the ethics of facial transplantation (especially regarding patient selection), there are still some issues that have gained less attention. For instance, how well are the patients prepared for the postoperative attention their cases are going to bring them? How is the medical community going to encourage those patients not to stay at home after the operation, but to participate at their communities? And although doctors are cautious about the emotional toll of donor families meeting recipients, there 
Page 2 of 2

have been recent examples of patients who had face transplants in Turkey and the United States and had the chance to meet relatives of their donors [12].

As face transplantation becomes more and more common, the need for donors will raise [13]. And one of the major questions in today's field of face transplantation is not only "how are we going to allocate these donors" but also "whether the medical community is prepared to lead such a donor allocation". Facial transplantation has raised so many ethical issues due to the specific characteristics of the face compared to the donation of other organs such as the heart, the lungs or the liver. "The face is the soul of the body", an expression used by Ludwig Wittgenstein. And the face is the only part of our body which we cannot truly hide. Face plays an essential role in the way we identify ourselves but also in the way others identify us.

According to the local legislations of each country, donor allocation is easier in some countries (i.e. Spain, Austria), whereas in other countries (i.e. Germany) informed consent of the donor or of his family is essential in order to allocate organs for transplantation. Society in general understands the need for donor organs and the medical necessity for transplantation. Thus, either through public campaigns or through appropriate discussions performed by specialized medical professionals the allocation of inner organs has been easier during the last decades [14]. Nonetheless, it still remains a delicate issue - especially when family members have to take such a serious decision that is always combined with the acceptance of the loss of a beloved relative. But somehow the human mind seems to accept the donation of "invisible organs" (i.e. heart, lungs) easier compared to the donation of "visible organs" (i.e. cornea). And these are the situations that demand a very delicate handling by the medical professionals.

Thus, imagine discussing with the family of a potential donor about the possibility of a face donation. Are medical professionals prepared to lead and perform such kind of discussions? Is the medical community convinced about the technical feasibility and the benefits of facial transplantation in order to convince a potential donor family? Is the medical community prepared to talk potential donor families into donating the face of their beloved one and accepting in that way that they have to perform a funeral without having the possibility to "kiss goodbye" their relative? And what about GP's and family doctors? They also play a substantial role in advising their patients about organ donation. But are they convinced about the benefits and the technical feasibility of facial transplantation? Furthermore, are they adequately trained or informed in order to help the allocation of potential face transplants? [15] And also we should not forget the ethical issues raised in possible pediatric face allotransplantation cases [16]. These are only few of the questions that arise when considering the future challenges of facial transplantation not only regarding the recipient but also regarding potential donors and their families as well as medical professionals.

\section{Conclusion}

Facial allotransplantation has been a controversial issue for many years, because it was mainly seen as an "experimental" surgical procedure. Nowadays, facial allotransplantation steadily proves its technical feasibility. And due to that more and more ethical issues arise. Many discussions address ethical issues concerning the recipient person and the society. There are also discussions addressing economical issues as well. Still there are other concerns that have to be studied as well. Ethical issues concerning the donors and the donor families as well as the medical community need to be addressed in a better way as the need for facial allotransplantation rises.

\section{References}

1. Murray JE, Tilney NL, Wilson RE (1976) Renal transplantation: a twentyfive year experience. 184: 565-573.

2. Devauchelle B, Badet L, Lengelé B, Morelon E, Testelin S, et al. (2006) First human face allograft: early report. 368: 203-209.

3. Barker JH, Stamos N, Furr A, McGuire S, Cunningham M, et al. (2007) Research and events leading to facial transplantation. 34: 233-250, ix.

4. Coffman KL, Siemionow MZ (2014) Ethics of facial transplantation revisited. 19: 181-187.

5. Edgar A (2009) The challenge of transplants to an intersubjectively established sense of personal identity. 17: 123-133.

6. Pirnay P, Foo R, Hervé C, Meningaud JP (2012) Ethical questions raised by the first allotransplantations of the face: a survey of French surgeons. 40: e402-407.

7. Hui-Chou HG, Nam AJ, Rodriguez ED (2010) Clinical facial composite tissue allotransplantation: a review of the first four global experiences and future implications 125: 538-546.

8. Robinson E, Rumsey N, Partridge J (1996) An evaluation of the impact of social interaction skills training for facially disfigured people 49: 281-289.

9. Royal College of Surgeons of England (2003) Facial Transplantation Working Party Report. London: Royal College of Surgeons of England.

10. Once 'Morally Objectionable,' Face Transplantation Now Seen as 'Feasible and Necessary' Procedure. ASPS (2013)

11. Kiwanuka H, Bueno EM, Diaz-Siso JR, Sisk GC, Lehmann LS, et al. (2013) Evolution of ethical debate on face transplantation. 132: 1558-1568.

12. http://www.cbsnews.com/news/man-with-face-transplant-meets-sisterof-his-donor/

13. American Society of Plastic Surgeons (2004) Science fiction of face transplants may be closer than you think; Reconstructive plastic surgeons perform miracle transplants now. American Society of Plastic Surgeons.

14. Hurlburt M (2007) Facial transplantation: understanding the interests of patients and hurdles to informed consent 13: RA147-153.

15. Renshaw A, Clarke A, Diver AJ, Ashcroft RE, Butler PE (2006) Informed consent for facial transplantation 19: 861-867.

16. Flynn J, Shaul RZ, Hanson MD, Borschel GH, Zuker R (2014) Pediatric facial transplantation: Ethical considerations. 22: 67-69. 